\title{
Impersonal Default Rules vs. Active Choices vs. Personalized Default Rules: A Triptych
}

\section{Citation}

Cass R. Sunstein, Impersonal Default Rules vs. Active Choices vs. Personalized Default Rules: A Triptych (Nov. 5, 2012)(unpublished manuscript, on file with author).

\section{Permanent link}

http://nrs.harvard.edu/urn-3:HUL.InstRepos:9876090

\section{Terms of Use}

This article was downloaded from Harvard University's DASH repository, and is made available under the terms and conditions applicable to Open Access Policy Articles, as set forth at http:// nrs.harvard.edu/urn-3:HUL.InstRepos:dash.current.terms-of-use\#OAP

\section{Share Your Story}

The Harvard community has made this article openly available.

Please share how this access benefits you. Submit a story.

\section{Accessibility}


Preliminary draft 11/5/2012

All rights reserved

\title{
Impersonal Default Rules vs. Active Choices vs. Personalized Default Rules: A Triptych
}

\author{
Cass R. Sunstein
}

\begin{abstract}
Impersonal default rules, chosen by private or public institutions, establish settings and starting points for countless goods and activities -- cell phones, rental car agreements, computers, savings plans, health insurance, websites, privacy, and much more. Some of these rules do a great deal of good, but others might be poorly chosen, perhaps because those who select them are insufficiently informed, perhaps because they are self-interested, perhaps because one size does not fit all. The existence of heterogeneity argues against impersonal default rules. The obvious alternative to impersonal default rules, of particular interest when individual situations are diverse, is active choosing, by which people are required to make decisions on their own. The choice between impersonal default rules and active choosing depends largely on the costs of decisions and the costs of errors. In complex and unfamiliar areas, impersonal default rules have significant advantages, but where people prefer to choose, and where learning is both feasible and important, active choosing may be best, especially if people's situations are relevantly dissimilar. At the same time, it is increasingly possible for private and public institutions to produce highly personalized default rules, which reduce the problems with one-size-fits-all defaults. In principle, personalized default rules could be designed for every individual in the relevant population. Collection of the information that would allow accurate personalization might be burdensome and expensive, and might also raise questions about privacy. But at least when choice architects can be trusted, personalized default rules offer almost all of the advantages of active choosing without the disadvantages.
\end{abstract}

\section{Introduction}

Consider the following:

1. In Germany, about 12 percent of people consent to be organ donors, whereas in Austria, the rate is 99.9 percent. We might speculate that this dramatic difference stems from different cultures, different norms, or extraordinarily effective educational campaigns in Austria, but the speculation would be wrong. Instead it results from law and more particularly from the default

\footnotetext{
Felix Frankfurter Professor of Law, Harvard Law School. This Essay is a very preliminary draft of the Maccabaean Lecture in Jurisprudence, to be delivered at the British Academy in March 2013. I am grateful to Elizabeth Emens and Eric Posner for valuable comments on a previous draft. I am also grateful to Daniel Kanter for valuable research assistance.
} 
rule. ${ }^{1}$ In Austria, consent is presumed, subject to opt out. In Germany, consent is not presumed, and people have to opt in.

2. Some people have been interested in increasing consumers' use of "green energy" - energy sources that do not significantly contribute to air pollution, climate change, and other environmental problems. While such energy sources are available in many places, few people choose them (notwithstanding the fact that in response to questions, they say that they would do $\mathrm{so}^{2}$ ). Nonetheless, two communities in Germany do show strikingly high levels of green energy use - well over 90 percent. ${ }^{3}$ This is a dramatic contrast to the level of participation in green energy programs in other German towns, which is around 1 percent. ${ }^{4}$ The reason for the difference is that in the two relevant communities, people are automatically enrolled in green energy programs, and they have to opt out. ${ }^{5}$

3. In the United States, savings rates have often been quite low, because people have delayed enrollment in pension plans. A number of employers have produced significant increases in savings through one simple initiative: make enrollment automatic, subject to opt out. The result of this initiative has been dramatically to increase participation rates. ${ }^{6}$

Those who devise default rules are choice architects, ${ }^{7}$ in the sense that they design the social background against which choices are made. It is not possible to dispense with a social background, and some kind of choice architecture is therefore inevitable. No less than social norms and available information, default rules are central features of choice architecture. Moreover, default rules, even or perhaps especially if they appear to be invisible, count as a prime "nudge." If private or public institutions establish a default rule, they do not force anyone to do anything. On the contrary, they maintain freedom of choice. ${ }^{9}$ Whether people must opt out or opt in, they are permitted to do so as they see fit. What is striking and somewhat mysterious is that default rules nonetheless have a large impact, because they tend to stick. ${ }^{10}$ If a private or public institution seeks to alter

${ }^{1}$ See Eric Johnson \& Daniel Goldstein, Do Defaults Save Lives?, 302 SCIENCE 1338 (2003), available at http://papers.ssrn.com/sol3/papers.cfm?abstract id=1324774; DUNCAN WATTS, EVERYTHING IS OBVIOUS 30-31 (2011).

${ }^{2}$ Daniel Pichert \& Konstantinos V. Katsikopoulos, Green Defaults: Information Presentation and Proenvironmental Behaviour, 28 J. ENVTL. PSYCHOL. 63 (2008). This difference is something of a mystery. It might be a product of the fact that it is not easy to find and select green energy. Alternatively, the survey setting may produce somewhat artificial answers.

${ }^{3}$ Pichert and Katsikopoulos, supra note.

${ }^{4}$ Id.

${ }^{5}$ Id.

${ }^{6}$ See Shlomo Benartzi, SAve More Tomorrow (2012).

${ }^{7}$ On the basic concept, see Richard THALER \& CASS R. SUNSTEIN, NUdGE (2008).

${ }^{8} I d$.

${ }^{9}$ The assumption here is that opting in and opting out are both easy and essentially costless. Freedom of choice is limited insofar as there are costs in switching from the default rule. See Cass R. Sunstein, Behavioral Economics and Paternalism, YALE L.J. (forthcoming 2013).

${ }^{10}$ See id.; Eric Johnson \& Daniel Goldstein, Defaults and Donation Decisions, 78 Transplantation 1713 (2004). 
outcomes, switching the default rule may be a highly effective route. With respect to health care, consumer protection, the availability of organs, energy use, environmental protection, savings, and much more, the choice of the default rule is exceedingly important. Public-spirited or self-interested people, in both the private and public spheres, might use default rules to produce outcomes that they deem desirable.

One of the most important tasks of a legal system is to establish default rules. Indeed, many policies operate through default rules, and contract law consists in large part of such rules. What happens if the parties are silent on whether employees may be fired only "for cause," or instead for whatever reason the employer deems fit? A default rule might specify the answer, and it might well "stick." In the law of contract, people often do not contract around default rules even if it is relatively costless for them to do so. Of course some legal rules are mandatory; they do not merely set the default. Employees are not allowed to opt out of the prohibition on racial discrimination or sexual harassment. But even in sensitive contexts, default rules might be important. For age discrimination, for example, the United States allows people to waive their rights at the point of retirement, subject to certain constraints. ${ }^{12}$

In this Essay, I have two goals. The first is to provide a general overview of what we now know about default rules - about when they have large effects and when they do not, and exactly why. The second goal is to make some progress in understanding the choice among three alternatives: impersonal default rules, active choosing, and personalized default rules. Most default rules are impersonal, in the sense that they do not distinguish among members of large groups to which they apply. Impersonal default rules might be chosen on several grounds. Perhaps there are no relevant differences among members of the groups affected by such rules, and hence impersonality is not damaging. Perhaps choice architects lack the information that would justify greater personalization, and hence impersonality is the only approach that is feasible. Perhaps active choosing would be an unnecessary and unhelpful burden, producing confusion and frustration without improving outcomes.

As we will see, however, active choosing can have significant advantages over impersonal default rules, especially when choice architects are ill-informed or untrustworthy and the relevant population is diverse. In the face of diversity, active choosing may reduce the mistakes associated with impersonal default rules, and may also promote learning. Unfortunately, active choosing can also impose high costs. Life is short, and people are busy, and if they were required to engage in active choosing in the many domains in which they now benefit from default rules, they would end up having time for little else. ${ }^{13}$ The great promise of personalized default rules is that they might eliminate the problems associated with impersonal ones without imposing the costs of active choosing. As default rules become more personalized, the advantages of active choosing start to diminish, because personalized approaches can handle the problem of

${ }^{11}$ See Samuel Issacharoff, Contracting for Employment, 74 TEX. L. REV. 1783 (1994).

${ }_{12}^{12} 20$ U.S.C. $\$ 626(\mathrm{f})(1)$ (2006). Note that the right is waivable for past violations, not for future violations.

${ }^{13}$ A highly relevant discussion is Anuj K. Shah et al., Some Consequences of Having Too Little, 338 SCIENCE 682 (2012). 
heterogeneity without requiring people to act at all. In many respects, personalized default rules promise to confer large social benefits. At the same time, it can be burdensome and expensive to produce accurate personalized default rules, and such rules might be used opportunistically by those who are motivated by their own self-interest, rather than the interests of potential choosers.

My basic conclusion is that the choice among impersonal default rules, active choosing, and personalized default rules cannot be made in the abstract. To know which is best, choice architects need to investigate the costs of decisions and the costs of errors. Four propositions are clear. First, impersonal default rules should generally be preferred to active choosing when the context is confusing and unfamiliar, when people would prefer not to choose, and when the population is not heterogeneous along any relevant dimension. Second, active choosing should generally be preferred to impersonal default rules when choice architects lack relevant information, when the context is familiar, when people would actually prefer to choose, and when there is relevant heterogeneity. Third, personalized default rules should generally be preferred to impersonal ones in the face of relevant heterogeneity. Fourth, personalized default rules (if accurate) have significant advantages over active choosing, because they produce benefits without real costs, at least if choice architects are trustworthy and if people are allowed to opt out. ${ }^{14}$

One of my basic claims is that in many domains, personalized default rules are the wave of the future, and for good reason. In ordinary life, family members and friends adopt, every day and in ways large and small (and often unconsciously), the functional equivalent of personalized default rules, by assuming that people will want in the future what they have wanted in the past -- or perhaps that they will want the same kinds of variety in the future that they have enjoyed in the past. For example, spouses and close friends select default options for restaurants, vacation spots, and even conversations, subject to opt out. As information accumulates about people's actual choices, many private and public institutions will be in a position to provide personalized default rules. ${ }^{15}$

\section{Why Default Rules Matter}

\section{A. Three Further Illustrations}

To appreciate the importance and potential of default rules, it will be useful to provide further illustrations. For the moment, we shall be dealing only with impersonal default rules. In due course, we shall explore their limitations as well and turn to more personalized alternatives.

1. Insurance. In the context of insurance, an unplanned, natural experiment showed that default rules can be very "sticky." $\mathrm{New}$ Jersey created a system in which the default

\footnotetext{
${ }^{14}$ A qualification is that personalized default rules do not promote learning; active choosing is preferable on that count.

${ }^{15}$ For relevant discussion, see Emir Kamenica et al., Helping Consumers Know Themselves, 101 AM. ECON. REV. 417 (2011).

${ }^{16}$ See Colin Camerer, Prospect Theory in the Wild, in ChOICES, VAlues, AND Frames 288, 294-95 (Daniel Kahneman \& Amos Tversky eds., 2000); Eric Johnson et al., Framing, Probability Distortions, and
} 
insurance program for motorists included a relatively low premium and no right to sue; purchasers were allowed to deviate from the default program and to purchase the right to sue by choosing a program with that right and also a higher premium. By contrast, Philadelphia offered a default program containing a full right to sue and a relatively high premium; purchasers could elect to switch to a new plan by "selling" the more ample right to sue and paying a lower premium.

In both cases, the default rule tended to stick. A strong majority accepted the default rule in both states, with only about $20 \%$ of New Jersey drivers acquiring the full right to sue, and $75 \%$ of Pennsylvanians retaining that right. Experiments confirm the basic effect, showing that the value of the right to sue is much higher when it is presented as part of the default package. ${ }^{17}$

2. Privacy. There is good reason to think that privacy rights will be greatly affected by the default rule. Suppose that a public or private institution says that information about your behavior (for example, the websites that you visit) will not be shared with anyone unless you click on a button to allow information sharing. Now suppose that the same institution says that such information will be shared unless you click on a button to forbid such sharing. Will the results be the same? Far from it. ${ }^{18}$

If people are asked whether they want to "opt in" to information sharing, a lot of them will either ignore the question or decline -- on the ground that if their privacy is now protected, they will certainly not want to sacrifice that protection. In either case, their information will not be shared. If people are asked whether they want to opt out of information sharing, a lot of them will also ignore the question, or decline, on the ground that they might not want to lose the potential advantages of such sharing -- especially if they have to think a little bit, and read something complicated, in order to switch. In that case, their information will be shared. In the domain of privacy on the Internet, a great deal depends on the default rule.

3. Vacation time. Might people's workplace benefits, such as vacation time, depend on the legal default rule? To answer that question, consider a simple experiment that I conducted a few years ago. ${ }^{19}$ About seventy-five randomly chosen law students were asked to answer question 1, and about seventy-five randomly chosen law students were asked to answer question 2. Note that the answers to these two questions were in many respects quite realistic. Law students are very much in the position of trading off variables in the selection of work, and both vacation time and salary matter to their decisions.

Insurance Decisions, in Choices, VAlues, AND Frames 244, 238 (Daniel Kahneman \& Amos Tversky eds., 2000). I draw in this paragraph, and in the discussion of the vacation study, from Cass R. Sunstein, Switching the Default Rule, 77 NYU L. REV. 106 (2002).

${ }^{17}$ Id. at $235-38$.

${ }^{18}$ See Eric Johnson et al., Defaults, Framing and Privacy: Why Opting in-Opting Out, 13 MARKETING LETTERS 5 (2002). A helpful discussion is Rebecca Balebako et al., Nudging Users Towards Privacy on Mobile Devices (2011), available at http://www.andrew.cmu.edu/user/pgl/paper6.pdf.

${ }^{19}$ See Sunstein, supra note. 


\section{Question 1:}

Imagine that you have accepted a job with a law firm in a large city. Your salary will be \$120,000. Under state law, all companies must provide nonmanagerial employees, including associates at law firms, with a minimum of two weeks in vacation time each year.

Suppose that the firm that you have chosen tells us that it will allow you to have two extra weeks of vacation, but at a somewhat reduced salary. What is the most that you would be willing to pay, in reduced salary, to obtain those two extra weeks of vacation time? (Assume that no adverse consequences could possibly come to you from bargaining for that extra vacation time.)

\section{Question 2:}

Imagine that you have accepted a job with a law firm in a large city. Your salary will be \$120,000. Under state law, all companies must provide nonmanagerial employees, including associates at law firms, with a nonwaivable minimum of two weeks in vacation time each year. State law also provides that all companies must provide nonmanagerial employees, including associates at law firms, with a waivable extra two weeks in vacation time each year. The extra two weeks can be waived only as a result of "explicit, noncoerced agreements" between the parties.

Suppose that the firm that you have chosen would be willing to pay you a certain amount, in extra salary, to get you to waive your right to the two extra weeks in vacation time. What is the least that the firm would have to pay you, in extra salary, to give up those two extra weeks? (Assume that no adverse consequences could possibly come to you from your refusal to waive, or from your demanding a high amount to waive.)

The results were dramatic. If the legal default rule includes more vacation time, people will demand a great deal to give it up; if the legal default rule does not include more vacation time, people will not pay a great deal to "buy" it. More specifically, the median willingness to pay (question 1) was $\$ 6000$, whereas the median willingness to accept (question 2) was $\$ 13,000$. The medians did not significantly vary between firstyear law students and law students in their second and third years. The only noteworthy difference was that about four first-year students refused to name any amount, saying that no dollar figure would be "enough to make me give up my vacation." These answers were excluded, and hence the observed difference in medians, of more than two-to-one, can be said to understate the real difference in responses.

\section{B. Explanations}


A great deal of research explores exactly why default rules have such a large effect on outcomes. ${ }^{20}$ There appear to be three contributing factors.

1. Inertia. The first involves inertia and procrastination. To change the default rule, people must make an active choice to reject that rule. They have to focus on the relevant question - whether they should be automatically enrolled in a savings plan, or whether they should have green energy, or whether they would gain or lose from a privacy policy. Especially if the question is difficult or technical, it is tempting to defer the decision or not to make it at all. In view of the power of inertia and the tendency to procrastinate, people may simply continue with the status quo.

Consider in this regard a study of television viewing, where inertia exerts a powerful force. ${ }^{21}$ As programs become more popular, the programs that follow them become more popular too, simply because the current channel is the default. More particularly, a ten percent increase in the popularity of the preceding program leads to a remarkable twothree percent increase in the audience for the following program. ${ }^{22}$ A striking finding is that stations exploit this behavior when scheduling their programs - and if they did not, they would lose up to 40 percent of their profits. ${ }^{23}$

For television programs, of course, all that is needed is to switch the channel, and channel-switching is hardly difficult. Opting in or opting out of default rules might be equally easy, but in many cases, it involves some thinking and some risk. The default rule might stick simply because people do not want to engage in that thinking and take that risk. Even if they want to do so, they might decide that they will do so tomorrow - and tomorrow never comes.

2. Endorsement. The second factor involves what people might see as an implicit endorsement of the default rule. If choice architects have explicitly chosen that rule, people may believe that they should not depart from it unless they have private information that would justify a change. ${ }^{24}$ Suppose, for example, that the default choice is green energy, or that a public or private employer automatically enrolls employees into a particular pension plan. It is tempting to think that experts, or sensible people, believe that these are the right courses of action. Those who are deciding whether to opt out

\footnotetext{
20 See, e.g., William G. Gale, J. Mark Iwry \& Spencer Walters, Retirement Savings for Middle- and Lower-Income Households: The Pension Protection Act of 2006 and the Unfinished Agenda, in Automatic 11, 13-14 (William G. Gale et al. eds., 2009); Isaac Dinner et al, Partitioning Default Effects: Why People Choose Not to Choose 3 (Nov. 28, 2010) (unpublished manuscript), available at http://ssrn.com/abstract=1352488; Gabriel D. Carroll et al, Optimal Defaults and Active Choices, 124 Q. J. ECON. 1639, 1641-43 (2009).

${ }^{21}$ See Constanca Esteves-Sorenson \& Fabrizio Perretti, Micro-Costs: Inertia in Television Viewing 122 ECON. J. 867 (2012).

${ }^{22}$ Id.

${ }^{23} \mathrm{Id}$.

24 See Craig R.M. McKenzie, Michael J. Liersch \& Stacey R. Finkelstein, Recommendations Implicit in Policy Defaults, 17 Psychol. SCI. 414, 418-19 (2006); Brigitte C. Madrian \& Dennis F. Shea, The Power of Suggestion: Inertia in 401(k) Participation and Savings Behavior, 116 Q. J. ECON. 1149, 1182. Of course it is not true that all defaults are chosen because they produce the best outcomes for people.
} 
might trust the choice architects well enough to follow their lead. Many people appear to think that the default was chosen by someone sensible and for a good reason. Especially if they lack experience or expertise, they might simply defer to what has been chosen for them. One implication of this explanation - suggestive of a method for testing whether inertia or instead perceived endorsement is making the default rule stick - is that if choosers do not trust the choice architect, they will be far more likely to opt out.

3. Reference point. The default rule might establish the reference point for people's decisions. Consider in this regard the behavioral finding of loss aversion. People dislike losses far more than they like corresponding gains, ${ }^{25}$ and whether a loss or a gain is involved does not come from nature or from the sky. The default rule determines what counts as a loss and what counts as a gain.

To appreciate the power of loss aversion and its relationship to default rules, consider an ingenious study of teacher incentives. ${ }^{26}$ Many people have been interested in encouraging teachers to do better to improve their students' achievements. The results of providing economic incentives are decidedly mixed; unfortunately, many of these efforts have failed. ${ }^{27}$ But the relevant study enlists loss aversion by resetting the default. The authors gave teachers money in advance and told them that if students did not show real improvements, the teachers would have to give the money back. The result was a significant increase in math scores - indeed, an increase equivalent to a substantial improvement in teacher quality. The underlying idea here is that losses from the status quo are especially unwelcome, and people will work hard to avoid those losses.

In short, what counts as a loss depends on the reference point, which is established by the default rule. ${ }^{28}$ Suppose, for example, that employees are receiving $\$ 5000$ per month in take-home salary, and that the question is whether they want some of that amount to be deducted for savings. If so, employees might decline. But if employees are receiving \$4800 per month in take-home salary and \$200 per month is going into savings, they might not complain -- and they might strongly resist the idea of taking away that \$200 per month from savings. With respect to the power of default rules, several of the findings described thus far are plausibly attributable to loss aversion.

In many areas, loss aversion matters and helps to explain the effect of the default rule. Energy use and environmental protection are among them. If, for example, the default rule favors energy-efficient light bulbs, and people are asked whether they want

\footnotetext{
25 See Richard H. Thaler, Daniel Kahneman \& Jack L. Knetsch, Experimental Tests of the Endowment Effect and the Coase Theorem, in RichaRd H. THALER, QuASI RATIONAL ECONOMICS 167, 169 (1994); A. Peter McGraw et al, Comparing Gains and Losses, 21 PsYCHOL. SCI. 1438, 1444 (2010). Vivid evidence of loss aversion can be found in David Card and Gordon B. Dahl, Family Violence and Football: The Effect of Unexpected Emotional Cues on Violent Behavior, 126 Q. J. ECON. 103, 105-06, 130-35 (2011) (finding an increase in domestic violence after a favored team suffers from an upset loss in football).

${ }^{26}$ See Roland Fryer et al., Enhancing the Efficacy of Teacher Incentives through Loss Aversion (Nat'1 Bureau of Econ. Research, Working Paper No. 18237, 2012), available at http://www.nber.org/papers/w18237.pdf.

${ }^{27}$ See id.

28 See Dinner et al, supra note $\mathrm{X}$ at *5-6.
} 
less efficient bulbs, then the loss (in terms of reduced efficiency) may loom large and they will continue to purchase energy-efficient light bulbs. ${ }^{29}$ But if the default rule favors less efficient (and initially less expensive) light bulbs, and people are asked whether they want to pay more for efficient ones, then the loss in terms of upfront costs may loom large, and there will be a tendency to favor less efficient light bulbs.

The explanation for the stickiness of the default rule may be relevant to the decision about whether to change it. Suppose that people do not alter the default rule because they believe that choice architects have implicitly endorsed it. If so, choice architects should consider themselves relatively free to adopt the default rule that they do in fact endorse. The issue might seem more difficult if the default rule sticks as a result of inertia or loss aversion, where there might seem to be a risk that choice architects are manipulating people or exploiting behavioral findings. ${ }^{30}$ Even in such cases, however, the default rule is inevitably having an influence, and hence the question would seem to be which default rule is best. That question must be addressed on the merits.

\section{Nonsticky (Impersonal) Default Rules}

In some circumstances, impersonal default rules do not stick. To understand the uses and limits of this particular kind of nudge, and to see why active choosing and personalized defaults might be better, we need to specify those circumstances.

\section{A. Clear Preferences and Extreme Defaults}

Consider the question of marital names. ${ }^{31}$ When people marry, all states in the United States have the same default rule: Both men and women retain their pre-marriage names. But there is nothing inevitable about the current default rule. We could easily imagine a large number of alternatives, for example:

- The husband's name stays the same, and the wife's name changes to that of her husband. Indeed, that approach, however discriminatory, would mimic people's actual choices, at least in the United States.

- The husband's name changes to that of his wife, and the wife's name stays the same.

- The spouses' names are hyphenated.

- The spouses' names are changed to Skywalker, or Longstocking, or Obama, or Gaga, or Potatohead.

29 See id. at *12-14; THALER \& SUNSTEIN, supra note.

${ }^{30}$ Riccardo Rebonato, TAKIng Liberties (2012); Joshua Wright and Douglas H. Ginsburg, Behavioral Law and Economics: Its Origins, Its Fatal Flaws, and Its Implications for Liberty, 106 Nw L Rev (2012); Edward Glaeser, Paternalism and Psychology, 73 U. CHI. L. REV. 133 (2006).

${ }^{31}$ The best discussion is Elizabeth F. Emens, Changing Name Changing: Framing Rules and the Future of Marital Names, 74 U. CHI. L. REV. 761 (2007). 
What are the effects of the current rule? In the overwhelming majority of cases, American men do stick with the default. Very few men change their names. By contrast, the overwhelming majority of American women do so -80 percent. $^{32}$ In that respect, the default rule seems to have little impact on women.

Why doesn't the default rule stick for women? Three factors seem to be important. First, many women (undoubtedly affected by social norms) affirmatively want to change their names, and their desire is not unclear. ${ }^{33}$ This is not a complex or unfamiliar area in which people are unclear about their preferences. Second, the issue is salient to them, and because marriage is a defining event, the timing of the required action is relatively clear as a social matter at least. Procrastination and inertia are therefore less important. Third, the change of name is, for some or many of those who do it, a kind of celebration. It is not the sort of activity that people seek to defer. When the relevant conditions are met clear preferences, clear timing, and positive feelings about "opt in" - the default rule is unlikely to matter much. ${ }^{34}$

Indeed, clear preferences are likely to be sufficient to ensure that the default rule will not stick. If preferences are clear, inertia will be overcome; people will not be much moved by the endorsement in the default rule ${ }^{35}$; and loss aversion will be far less relevant, in part because the clear preference helps define the reference point from which losses are measured. Suppose that employees are automatically enrolled into a plan that puts 80 percent of their income into savings, or 60 percent of their income into their nation's treasury (after taxes!), or 20 percent of their income into their worst enemy's savings account, ${ }^{36}$ or 10 percent of their income into the toilet. Most of them will undoubtedly opt out. A study in the United Kingdom found that most people opted out of a savings plan, admittedly less horrible than those just described, but with an unusually high default contribution rate (12 percent of before-tax income). ${ }^{37}$ Only about 25 percent of employees remained at that rate after a year, whereas about sixty percent of employees shifted to a lower default contribution rate. Notably, people with lower incomes were more likely to stay at the unusually high contribution rate. ${ }^{38}$

\footnotetext{
${ }^{32} \mathrm{Id}$.

${ }^{33}$ To be sure, we do not know the full picture here, and the word "want" elides some important issues. In many cases, social norms exert a degree of pressure, and some husbands undoubtedly make their own preferences clear, thus affecting the choices of wives. See id. Social norms can operate as the equivalent of a default rule and overcome the legal default. It is possible that this account is, for many wives, the underlying story here.

${ }^{34}$ For a set of suggestions about whether and how to deal with this fact, see $i d$.

${ }^{35}$ The general point holds, but in the context of marital names, the issue may be more complex, especially in view of the evident power of the social norm and the fact that a default may suggest endorsement. See Emens, supra note $\mathrm{X}$, for detailed discussion.

${ }^{36}$ On using strategies of this sort as precommitment devices, see IAN AYRES, CARROTS AND STICKS (2010).

37 See John Beshears et al, The Limitations of Defaults *8 (Supt. 15, 2010) (unpublished manuscript), available at http:/www.nber.org/programs/ag/rrc/NB10-02,\%20Beshears,\%20Choi,\%20Laibson, $\%$ 20Madrian.pdf. ${ }^{38}$ Id.
} 
A clear implication is that "extreme" defaults are less likely to stick. A more puzzling implication, based on the lower incomes of those who stayed with the default in the study just described, is that default rules may be more sticky for low-income workers than for their higher-earning counterparts. One reason may be that low-income workers have a great deal to worry about, ${ }^{39}$ and so are less likely to take the trouble to think through and to alter the default rule. Another may be that low-income workers have less confidence in their own judgments, and so they allow the default allocation to stick.

There are other situations in which the default rule does not have a large impact. Workers are not so much affected if a significant fraction of their tax refund is defaulted into US savings bonds. In significant numbers, they opt out, apparently because they have definite plans to spend their refunds and do not have much interest in putting their tax refund into savings. ${ }^{40}$ The central finding -- that default rules will have a weaker effect, and potentially no effect, when people have a strong preference for a certain outcome -- is both a warning and an opportunity. It suggests that the ability to opt out can be an important safeguard against defaults that are unhelpful or affirmatively harmful.

\section{B. Strategic Behavior, Self-Interest, and Facilitating Opt-Out}

In some situations, defaults may not stick even though they are important safeguards. Suppose that self-interested people have a strong incentive to promote optout. If so, they might be able to take steps to achieve their goals. If green energy is far less profitable than more conventional energy sources, we can be confident than those who sell the latter will take aggressive steps to encourage people to opt out of a default rule in favor of green energy. If those steps are not only aggressive but also behaviorally informed, they might well succeed; they might, for example, enlist loss aversion to encourage opt-out. Here, then, is a serious obstacle to public-interested efforts to use defaults to produce desirable social change.

The problem is not hypothetical. Consider the regulatory effort in 2010 , by the Federal Reserve Board, to protect people from bank overdraft fees. ${ }^{41}$ The regulation forbids banks from charging a fee for overdrafts from checking accounts unless the accountholder has explicitly opted out and enrolled in the bank's overdraft program. ${ }^{42}$ One of the goals of the default rule is to protect customers, and especially low-income customers, from ending up taking the equivalent of extraordinarily high interest loans indeed, loans with interest rates of up to 7000 percent. ${ }^{43}$ In principle, the regulation

\footnotetext{
${ }^{39}$ See Abhitt BAnerJee \& Esther Duflo, Poor EConomics (2010); Shah et al., Some Consequences of Having Too Little, supra note.

40 See Erin Todd Bronchetti et al, When a Nudge Isn't Enough: Defaults and Saving among Low-Income Tax Filers 4 (Nat'l Bureau of Econ. Research, Working Paper No. 16887, 2011), available at http://www.nber.org/papers/w16887. Note, however, that the "default" in this study consisted of a mere statement on a form. Id. at 11 . The line between the use of such a "default" and active choosing is relatively thin.

${ }^{41}$ See Laurie Willis, When Nudges Fail: Slippery Defaults, 80 U. CHI. L. REV. (forthcoming 2012).

${ }^{42}$ See id.

${ }^{43} I d$.
} 
should have had a large effect, and an understanding of the power of default rules helped to motivate it. But the available evidence suggests that the effect may well be modest, because people are opting out of the default in large numbers.

What explains this modest effect? As Laurie Willis has shown in an important and illuminating article, ${ }^{44}$ a central reason is that banks much dislike the regulation, want to be able to charge overdraft fees, and have used a number of tools to facilitate opt-out. They have taken steps to make opt-out as easy as possible - for example, simply by pushing a button on an ATM. They have also engaged in active marketing and created economic incentives to persuade people to opt-out. Showing an implicit (or perhaps even explicit) understanding of behavioral economics, they exploit loss aversion and consumer confusion to encourage accountholders to think that they will lose money if they do not opt out. Consider the following excerpt from one bank's marketing materials, explicitly enlisting loss aversion ${ }^{45}$ :

YES: KEEP MY ACCOUNT WORKING THE SAME WITH SHAREPLUS ATM AND DEBIT CARD OVERDRAFT COVERAGE

NO: CHANGE MY ACCOUNT TO REMOVE SHAREPLUS ATM AND DEBIT CARD OVERDRAFT COVERAGE

As Willis quotes a bank employee, "People are scared of change so they'll opt-in [to overdraft] to avoid change. ${ }^{46}$ There is a large contrast here with the retirement context, where providers enthusiastically endorse automatic enrollment. ${ }^{47}$ The general lesson is that if regulated institutions are strongly opposed to the default rule, and have easy access to their customers, they may well be able to use a variety of strategies, including behavioral ones, to encourage people to move in their preferred directions. In some circumstances, it may be necessary to take further steps to make the default rule sticky, if ensuring that it sticks is indeed the goal.

\section{Which Default Rule?}

In many domains, choice architects can achieve desirable goals, and do so while maintaining freedom of choice and at low cost, by selecting good default rules and by avoiding harmful ones. But which default rule should choice architects select ${ }^{48}$ ? How do we know which is good and which is harmful?

\section{A. Informed Choices}

\footnotetext{
${ }^{44} \mathrm{Id}$

${ }^{45}$ See id.

${ }^{46}$ See id.

${ }^{47}$ See, e.g., Automatic Enrollment and Increases, NATIONwIDE, http://www.nationwide.com/automaticenrollment.jsp (last visited Nov. 3, 2012).

${ }^{48}$ For relevant discussion, overlapping that here, see THALER \& SUNSTEIN, supra note.
} 
These are large questions, and if they are to be answered by reference to the most basic social commitments, we could imagine a number of possible answers. ${ }^{49}$ Some people might think that the best approach promotes economic efficiency. Others might believe that we should choose default rules that are most fair or just. Still others might believe that choice architects should decide which rules would maximize social welfare and choose accordingly. ${ }^{50}$

Begin with the standard case in which there are no (or modest) third-party effects. I propose that we might bracket the deepest questions and obtain an incompletely theorized agreement on a preferred approach -- that is, an agreement that can attract support from people with diverse foundational commitments, and from those who are not sure about which commitments they believe to be foundational. ${ }^{51}$ The preferred approach is to select the default rule that reflects what most people would choose if they were adequately informed. ${ }^{52}$ The advantage of this approach is that it should appeal, at least in general, to those who focus on efficiency, welfare, autonomy, or fairness. ${ }^{53}$ If we know that a particular default rule would place people in the situation that informed people would bargain their way to or select, we have good reason to select that default rule (with the understanding that those who differ from the majority may opt out). Suppose that we know that 80 percent of people, given a great deal of information, would choose green energy. That is a strong reason to favor automatic enrollment in green energy.

To be sure, it might well be necessary to do a great deal of work in order to identify the approach that informed people would choose. (As we shall see, this is a point in favor of active choosing.) And in a contractual setting, a default rule that seems to favor one side may not, of course, be the provision to which informed people would bargain. For example, informed workers and informed employers may not bargain their way toward a "good cause" provision for the termination of employment if the consequence of that provision would be to impose high costs on employers (and eventually on employees) without providing important or meaningful safeguards for workers. Informed customers and energy companies may refuse to bargain their way to a particular "green" default if it turns out to impose much higher costs. (Of course the existence of third party effects, taken up below, may argue in favor of green defaults.)

On this count, actual evidence about informed choice is extremely important. It would be useful to assemble information about the level of opt-out under various

\footnotetext{
${ }^{49}$ For valuable discussion of possibilities, see Matthew Adler, Well-BeING AND FAIR Distribution: BEYOND COST-BENEFIT ANALYSIS (2011).

${ }^{50}$ Some of these issues are briefly discussed in Sunstein, Switching the Default Rule, supra note; Adler, supra note, engages the philosophical issues.

${ }_{52}^{51}$ See Cass R. Sunstein, Legal Reasoning and Political Conflict (1996).

52 See N. Craig Smith, Daniel G. Goldstein, and Eric J. Johnson, Smart Defaults: From Hidden Persuaders to Adaptive Helpers 15-16 (INSEAD Bus. Sch., Working Paper No. 2009/03/ISIC, 2009), available at http://ssrn.com/abstract=1116650.

${ }^{53}$ To be sure, there are some complications. Some people who are concerned with fairness, or with distribution, may fear that because of the bargaining power of one or another side, informed people will settle on an unfair agreement, and that a different default rule might be better. For present purposes, I put that point to one side. See Sunstein, Switching the Default Rule, supra note X, for relevant discussion.
} 
alternatives. ${ }^{54}$ If only two percent of people opt out under A, and fifty percent opt out under $\mathrm{B}$, we have reason to believe that $\mathrm{A}$ is better.

Of course it is possible that majority rule is too crude. Suppose that there are two default rules, A and B. Suppose that 55 percent of informed people would be relatively indifferent between A and B, but would slightly prefer A. Suppose too that because of their unusual situation, 45 percent of people would strongly prefer B. We should probably select B, because almost half of the population would much like it, and the (narrow) majority only cares a little bit. The example shows that it is important to ask not only about which approach would be preferred by informed people, but also about the intensity of their preferences.

The most natural way to think of the choice is in terms of costs and benefits. If a default rule turned out to stick, what would be the costs and what would be the benefits ${ }^{55}$ ? In the example just given, default rule B would almost certainly be best. We could imagine cases in which the choice between default rules is hard, and in such cases, active choosing might be better; I will return to this point.

Note, however, that the question of marital names suggests an interesting qualification to the idea that the default rule should track the choices of informed people. Taken seriously, that idea would suggest that states should presume that men want to keep their premarital names and that women want to change their names to those of their husbands. But a default rule of this kind would be discriminatory, and it would almost certainly be found unconstitutional. ${ }^{56}$ The example shows that in some settings, informed choices lack authority if they run afoul of important social commitments, at least if government proposes to use those choices as a basis for policy. ${ }^{57}$

\section{B. Penalty Defaults}

If choice architects do not know which rule would be chosen by informed people, standard contract theory suggests that they might favor a "penalty default," designed to elicit that information. ${ }^{58}$ For example, employees sometimes lack information about their legal rights, showing excessive optimism, ${ }^{59}$ and a default rule that gives certain rights to employees might increase the flow of information between the parties and to the legal system. ${ }^{60}$ Suppose that if the default rule confers certain rights on employees - say, to job security -- employers will want to "buy" those rights. If this is the case, we will see a

${ }^{54}$ See THALER \& SUNSTEIN, supra note.

${ }^{55}$ Distributional issues may of course matter as well. See Sunstein, Switching the Default Rule, supra note; Adler, supra note.

${ }^{56}$ See Emens, supra note.

${ }^{57}$ The domain of marital names overlaps, in this regard, with that of racially based adoption policies. See R. Richard Banks, The Color of Desire, 107 YALE L.J. 875 (1998).

${ }^{58}$ For a much-cited discussion, see Ian Ayres \& Robert Gertner, Filling Gaps in Incomplete Contracts: An Economic Theory of Default Rules, 99 YALE L.J. 87 (1989).

${ }^{59}$ See Richard B. FreEMAN \& JOEl Rogers, What Workers WANT 118-22 (1999).

${ }^{60}$ See Issacharoff, supra note, at 1783. 
system in which certain information is disclosed to employees, simply as part of the process by which employers bargain. A default rule that protects workers might give them important information when they would otherwise overestimate their legal rights. ${ }^{61}$

\section{Third-Party Effects}

If there are third-party effects, of course the assessment of default rules will be affected. Suppose that under default rule A, significant costs are imposed on third parties, but that under default rule $\mathrm{B}$, those costs are avoided. If so, B is clearly preferable. In the case of default rules for organ donations and energy, this possibility is not hypothetical. A default rule in favor of organ donation would of course produce significant benefits to third parties. ${ }^{62}$ In addition, we could easily imagine energy choices that would impose lower environmental and other costs; green defaults might be justifiable on that ground.

In such cases, there is a strong argument for preferring the default rule that reduces those costs. Indeed, we might not be in the domain of mere default rules. If B prevents the imposition of serious costs on third parties, then there is a strong argument that it should be a mandate, not subject to opt-out. But we could imagine cases in which the existence and magnitude of third-party effects is disputed, and in such (admittedly unusual) cases, the best approach might be a default rule that prevents such effects.

\section{Risks: Self-Interest, Mischief, and More}

Default rules can of course be badly chosen or misused by private and public institutions alike. In fact some such rules can be extremely harmful. Imagine, for example, a voting system that says that if you do nothing, your vote will be registered as favoring the incumbent - but that you can opt out if you like. Or imagine a nation that defaults you into a certain political party or religion - but that allows you to opt out. Or a rental car company that defaults you into all sorts of insurance policies and payment plans that are essentially a waste of money - but that allows you to opt out.

Fortunately, market forces constrain some of the most harmful default rules. Competitive markets impose real limits on bad defaults. Before long, customers are not likely to go to companies that choose a series of such defaults. For this reason, many default rules are helpful rather than harmful; for example, the default settings for computers and cell phones are generally in the interest of customers. In some cases, however, companies may have an incentive to promote unhelpful defaults, especially when they are dealing with fine print, and when the relevant attributes of the product are shrouded and not salient. ${ }^{63}$

\footnotetext{
${ }^{61}$ On workers' ignorance of their legal rights, see FREEMAN \& ROGERS, supra note, at 118-122. This point is merely a factor, of course, rather than a conclusive argument.

${ }^{62}$ Thaler and Sunstein, NUDGE, supra note, urge a form of active choosing in this context.

${ }^{63}$ See OREn BAR-Gill, Seduction By CONTRACt (2012).
} 
Consider in this regard the practice of "negative option marketing." This practice occurs when people who accept a "free" product are automatically enrolled in a plan or program that carries a monthly fee (unless they explicitly opt out) ${ }^{64}$ Customers might, for example, receive a hotel room for free -- but as a result, they might be enrolled in a program that charges them $\$ 15$ per month. The monthly charge might be mentioned quietly and obscurely if at all, and if it is mentioned, people might be given (quietly) the option to opt out. ${ }^{65}$ In some cases, negative option marketing has a most unfortunate effect, which is that it uses a default rule to exploit the tendency toward inertia in a way that can cost people a great deal of money. Customers might not see the monthly bill, or if they see it, they might assume that all is well, and they might not cancel the plan until they have (automatically) paid a great deal. In the United States, the Federal Trade Commission has expressed serious concerns about this kind of marketing. ${ }^{66}$

It is easy to imagine both private and public analogues. Consider, for example, an automatic enrollment policy that puts an unreasonably large percentage of employees' salary into savings, or that enrolls them in a health insurance plan that is a bad deal for their circumstances, or that signs them up for an exercise plan that they do not need and perhaps hate. Automatic enrollment can be a waste or even a disaster. Lest this point be misunderstood, recall that the risk, important though it is, does not argue against default rules in general. We cannot do without them. The question is which ones are best, not whether to have one. (Active choosing is a qualification, to be discussed very shortly.)

To evaluate the use of automatic enrollment, the particular circumstances certainly matter. If automatic enrollment is not made clear and transparent to those who are enrolled, it can be considered a form of manipulation. The problem is worse if it is not in people's long-term interest.

\section{Active Choosing}

A distinctive approach, sometimes worth serious consideration, is this: Avoid any default rule and require active choices. ${ }^{67}$ Those who greatly distrust private or public institutions, and who want to avoid any kind of steering by them, will have considerable interest in active choices. They will want to deny default rules of any kind and put the key questions to people themselves. As we shall see, this approach has

${ }^{64}$ See 16 C.F.R. $\$ 425$ (2012); Fed. Trade Comm., Negative Options 5 (2009), available at http://www.ftc.gov/os/2009/02/P064202negativeoptionreport.pdf.

${ }^{65}$ I received a little lesson about this problem myself, when my credit card company graciously offered to provide me with a free three-month subscription to several magazines of my choice. Many years later, I found myself subscribing to those magazines, even though I didn't like them, and even though after the three-month period, I was automatically subscribing for full price. It was not until I faced the prospect of government employment, and the resulting salary cut, that I cancelled my subscriptions.

${ }^{66}$ See note supra.

${ }^{67}$ See Carroll et al., supra note. 
special advantages in the face of heterogeneity - especially if default rules would be impersonal.

\section{A. Life Without Defaults}

1. The basic idea. With active choices, people are required to make an actual decision among the various options; they are not defaulted into any particular alternative. With respect to health care, privacy, organ donation, and savings, for example, choice architects might reject both opt-out and opt-in and simply require people to indicate their preferences.

It is reasonable to speculate that active choosing would produce higher participation rates than opt-in but lower than opt-out, and indeed the speculation is supported by what we currently know. For example, active choosing has been found to result in far higher levels of savings than default rules that require people to opt in (but lower than automatic enrollment). ${ }^{68}$ Return to the question of privacy. Most web browsers currently default people into a situation in which their movements are visible and can be tracked. Another possibility would be to ask customers -- the first time they open the browser or periodically -- about the privacy setting that that they prefer, and perhaps to prevent them from proceeding until they answer. A reasonable guess is that this approach would produce more privacy than they currently enjoy. ${ }^{69}$

2. Active, but influenced, choosing. It is also possible to imagine a variety of variations on active choosing. For example, active choosing might be "enhanced," or influenced, in the sense that one of the choices might be highlighted or favored, perhaps through the use of behaviorally informed strategies. ${ }^{70}$ If choice architects seek to avoid a default rule but nonetheless to promote selection of one of the options, they might list it first, or use bold or a large font, or adopt verbal descriptions that make it especially salient or appealing.

In one study, choice was "enhanced," in the sense of being influenced, by enlisting loss aversion to discourage selection of the option disfavored by the experimenters. The experimenters introduced several different messages in the following way:

We would like you to imagine that you are interested in protecting your health. The Center for Disease Control indicates that a flu shot significantly reduces the risk of getting or passing on the flu virus. Your employer tells you about a hypothetical program that recommends you get a flu shot this Fall and possibly save \$50 off your bi-weekly or monthly health insurance contribution cost.

\footnotetext{
${ }^{68}$ See id. at 1670.

${ }^{69}$ Whether that would be desirable is of course another question.

${ }^{70}$ See Punam Anand Keller et al., Enhanced Active Choice: A New Method to Motivate Behavior Change, 21 J. CONSUMER PSYCHOL. 376 (2011).

${ }^{71}$ Id.
} 
In the opt-in condition, people were asked to "Place a check in the box if you will get a Flu shot this Fall." In a neutral active choice condition, people were asked to "Place a check in one box: I will get a flu shot this Fall or, I will not get a flu shot this Fall." With enhanced or influenced choice, people were asked to choose between two alternatives: "I will get a Flu Shot this Fall to reduce my risk of getting the flu and I want to save $\$ 50$ or, I will not get a Flu Shot this Fall even if it means I may increase my risk of getting the flu and I don't want to save \$50." Compared to opt-in, the active choice condition led to a significant increase in the percentage of people who would get a flu shot -- and the percentage was highest when active choice was influenced. ${ }^{72}$

There is an obvious parallel here with the efforts of banks to promote opt out by enlisting loss aversion and other behaviorally informed strategies. The principal point is that active choosing can be more or less neutral with respect to the relevant options. As the choice architect becomes decreasingly neutral, active choosing starts to look closer to a default rule.

\section{B. In Favor of Active Choosing}

Let us put the question of influence to one side and assume that if choice architects favor active choosing, they will remain neutral and not attempt to affect the choice. What might be said on behalf of this approach?

The initial point is that because a decision is required, active choosing overcomes inertia. If inertia (and procrastination) are playing a significant role, active choosing may be far better than opt-in. Consider savings plans, health insurance, and privacy settings. The problem with opt-in is that it will likely ensure that some people end up with outcomes that they would not prefer if they were to make a choice. A key virtue of active choosing is that it increases the likelihood that people will end up with their desired outcomes.

In addition, active choosing is a safeguard against uninformed or self-interested choice architects. When choice architects lack relevant information, so that the chosen rule might be harmful to some or many, there are significant advantages to active choosing. Suppose that a private institution is producing the default rule, and it really does not know a great deal about what informed people would choose. In the context of ice cream flavors, tablets, cell phones, and sneakers, active choosing is far better than an impersonal default rule. The same is true for many activities and goods provided by private institutions. Or suppose that the government is producing the default rule. If public officials are biased or inadequately informed, and if the default rule is no better than a guess, that rule might lead people in the wrong direction. The same point argues against a default rule, and in favor of active choosing, when self-interested private groups are calling for it even though it would not benefit those on whom it is imposed. Active choosing is much less risky on these counts. If we do not trust public officials - perhaps

${ }^{72}$ Id. 
because they do not know everything, perhaps because their motivations may not be pure - we might like active choosing best. ${ }^{73}$

Finally, and in some cases most important, active choosing appropriately handles diversity. As compared with either opt-in or opt-out, active choosing can have major advantages when the relevant group is heterogeneous, so that a single approach is unlikely to fit diverse circumstances. If one size does not fit all for health insurance or savings, then choice architects might want to ensure that people make choices on their own. For this reason, active choosing may be far better. In the face of diversity, an impersonal default rule may be especially harmful, because the power of inertia, or the force of suggestion, may mean that many people will end up in a situation that is not in their interest. People might be far better off if they are asked, "what health insurance plan do you like best?" than if they are automatically enrolled in a plan chosen by their employer.

\section{Against Active Choosing}

Notwithstanding its potential benefits, active choosing could also create serious problems. To see why, consider the words of Esther Duflo, one of the world's leading experts on poverty:

We tend to be patronizing about the poor in a very specific sense, which is that we tend to think, 'Why don't they take more responsibility for their lives?' And what we are forgetting is that the richer you are the less responsibility you need to take for your own life because everything is taken care for you. And the poorer you are the more you have to be responsible for everything about your life....Stop berating people for not being responsible and start to think of ways instead of providing the poor with the luxury that we all have, which is that a lot of decisions are taken for us. If we do nothing, we are on the right track. For most of the poor, if they do nothing, they are on the wrong track. ${ }^{74}$

Duflo's central claim is that people who are well off do not have to be responsible for a wide range of things, because others are making the relevant decisions, and to their benefit. In countless domains, choices are in fact "taken for us," and in a sense, such steps even promote our autonomy, because we are freed up to spend our time on other matters. $^{75}$

The point suggests an initial problem with active choosing, which is that it can impose large burdens on choosers. That burden may in fact be quite unwelcome. Suppose that the situation is unfamiliar and complicated. Suppose that people lack information or

\footnotetext{
73 See RicCARDo REBOnAto, TAKing Liberties (2012).

${ }^{74}$ The quotation can be found at Susan Parker, Esther Duflo Explains Why She Believes Randomized Controlled Trials Are So Vital, The Center for Effective Philanthropy Blog (June 23, 2011), http://www.effectivephilanthropy.org/blog/2011/06/esther-duflo-explains-why-she-believes-randomizedcontrolled-trials-are-so-vital/.

${ }^{75}$ See also Anuj K. Shah, supra note.
} 
experience. If so, active choosing may impose unjustified or excessive costs on people; it might produce frustration and appear to require pointless red-tape. Most consumers would not much like it if, at the time of purchase, they had to choose every feature of their cell phone plan or all of their computer's initial settings. The existence of defaults saves people a lot of time, and most of them may well be sensible and suitable. Few consumers would like to spend the time required to obtain relevant information and to decide what choice to make. As compared with a default rule, active choosing increases the costs of decisions, possibly significantly.

At the same time, active choosing can impose large burdens on providers. Defaults can be desirable and even important for those who provide goods or services. The reason is that they avoid costs, which might result in increases in prices (and thus harm consumers as well). Without a series of default rules, significant resources might have to be devoted to patient, tedious explanations and to going through the various options with consumers or users, who might not welcome the exercise.

A final point is that active choosing can increase errors. The goal of active choosing is to make people better off. But if the area is unfamiliar, highly technical, and confusing, active choosing might have the opposite effect. If consumers are required to answer a set of technical questions, and if the choice architects know what they are doing, then people will probably enjoy better outcomes with defaults.

\section{Personalized Default Rules}

My focus thus far has been on default rules that are impersonal, in the sense that they apply to all members of the relevant population, subject to the ability to opt out. But as I have noted, some default rules are highly personalized. Such approaches draw on available information about which approach best suits different groups of people, and potentially each individual person, in the relevant population. It is possible to imagine a continuum of personalized approaches, from most fine-grained to the most crude. In principle, choice architects could design default rules for every one of us. Perhaps this idea seems a bit like science fiction, but in the fullness of time, private and public institutions are likely to use a large number of personalized default rules. In fact we are already heading in that direction.

At least in general and in principle, the design of such personalized rules would be a great boon. The key advantage of such rules is that they are likely to be more accurate and thus beneficial than "mass" default rules. As technology evolves and information accumulates, it should be increasingly possible to produce highly personalized defaults, based on people's own choices and situations. For this reason, there will be promising opportunities to use default rules to promote people's welfare.

Every day, family members and friends use the equivalent of personalized default rules. They tend to know what people like in various domains, and with respect to conversation, food, restaurants, vacations, and more, they use those personalized defaults to people's benefit. They do not ask, in every case, for an active choice, which would make life more complicated and potentially even intolerable. Sometimes spouses order 
for one another at restaurants, or select clothing for them, using the functional equivalent of default rules and pursuant to an implicit delegation. ${ }^{76}$ Indeed, a large part of what it means to be a spouse, a partner, or a close friend is to be able to identify such defaults. (By contrast, strangers rely on impersonal ones, which may cause trouble.)

\section{A. Tracking and Extrapolating}

A personalized default might be based on people's own past choices or on those of people "like them." Consider, for example, Amazon.com, which provides recommendations to its customers on the basis of their past choices. Amazon.com knows that if customers like mysteries by a certain author, they will probably like mysteries by another author as well. Amazon.com might be thought to create something in the general vicinity of default rules, in the form of visible, salient choices. Of course the presentation of such choices is akin to advice and not literally a default, in the sense that if customers do nothing, they will purchase nothing. But the same technologies could easily be used to create defaults of multiple kinds.

Once enough information is available about Joe Smith, choice architects could design, for Joe Smith, default rules with respect health insurance, privacy, rental card agreements, computer settings, and much else. For some services, including travel, personalized defaults are have become familiar and common. If a website knows where customers like to sit on an airplane, and how they like to pay, it can use this information to generate outcomes (subject to customer revision). Personalized default rules can also be dynamic, in the sense that they can change over time. The best default rules or settings for a particular person, in one year, might be very different from those in the next year. In principle, the default rules could change on a daily or even hourly basis. As private and public institutions receive increasing amounts of information about each of us, this project is becoming increasingly feasible. Multiple websites are already moving in this direction, providing defaults for people based on their own past choices. In general, those defaults make life simpler and more convenient.

We could imagine a large variety of possibilities here. In some cases, defaults might be based directly on people's own past choices. In other cases, defaults might involve a degree of extrapolation from those choices. Choice architects might think that if people have made certain choices with respect to privacy in the domain of health insurance, they are likely to make certain choices with respect to privacy in other domains as well. Consider the familiar idea, with respect to consumer products, that if certain consumers actually like certain products, they are likely to like certain other products as well. If sufficient data are available, personalized default rules might be generated in this way.

\section{B. Information Acquisition and Privacy}

\footnotetext{
${ }^{76}$ A cautionary note here, at once amusing and sad, and suggesting that people often make significant mistakes about what their family members and friends like, is JOEL WALDFOGEL, SCROOGENOMICS (2008).
} 
One challenge is that for defaults to be personalized, choice architects must obtain a great deal of information. In some contexts, obtaining such information is essentially costless. On websites, people make repeated choices, and if choice architects know what they usually choose, they can make that usual choice the default. Return to the case of travel preferences, or consider shipping times and credit cards for book purchases. But in other cases, there will be no such track record, at least at the beginning, and acquisition of relevant information will be costly or perhaps impossible. Suppose, for example, that people are purchasing new computers, and the question is the appropriate privacy setting for them. Personalized default rules are unlikely to be feasible.

Even if they are feasible, there is an additional challenge, which is that if defaults are based on people's past choices, there is a potential concern about privacy. By hypothesis, choice architects can identify those choices, and some choosers will not be delighted by that fact. People might well object if others know that they tend to like (say) silly science fiction novels -- and that for that reason, they are being defaulted into a wide range of choices favored by people who like such novels. We might make a distinction here. Perhaps choice architects themselves - those who run relevant programs or websites know about people's past choices; in fact such knowledge would seem inevitable (though there may be retention issues). Alternatively, choice architects might reveal those choices to other people. It is easily imaginable that choosers would object to the latter even if they would not object to the former. If they object to the latter, sharing of that kind should probably not be permitted - and a prohibition on sharing will make it harder to generate personalized defaults.

There is a potential solution to the privacy problem, which is that choice architects might use active choosing or personalized default rules with respect to privacy itself. Perhaps choice architects know that Jones is fiercely protective of her privacy and that in the face of any kind of doubt, she prefers to prevent other people from knowing about her behavior and her choices. If so, that very knowledge can be used to produce privacyprotective default rules. In the case of doubt, active choosing might be selected, so that people do not give up privacy unless they explicitly state their willingness to do so. With respect to privacy, there is a great deal of heterogeneity, which argues for active choosing.

\section{Demographics}

Less ambitiously, personalized default rules might be based on group characteristics, such as geographical or demographic variables. For example, age and income might be used in determining appropriate default rules for retirement plans. In fact this approach is already standard. For example, universities typically default faculty members into what seems to be an appropriate plan (subject of course to easy out). With respect to employees over sixty, the default allocation might be different from what it would be with respect to employees who are thirty, and for those with large incomes, the default might be different from what it would be for those who are making a little. The general idea is that your default rules would track what would be best for "people like you." 
Evidence suggests that for retirement plans, default rules that respect diversity (especially with respect to age) are indeed feasible - and that they can increase the probability of enrollment in the default plan by 60 percent. They can also create very large gains for participants. ${ }^{77} \mathrm{We}$ could easily imagine similar approaches to health insurance, credit cards, cell phones, mortgages, and much more.

\section{Conclusion}

Whether or not we notice them, default rules are omnipresent. They establish settings for many activities and goods, including cell phones, rental car agreements, computers, savings plans, health insurance, and energy use. ${ }^{78}$ In countless domains, they identify the consequences if choosers do nothing. In part because of the power of inertia, default rules tend to stick.

When the relevant group is not diverse, and when an impersonal default rule will satisfy the informed preferences of the members of that group, it is probably most sensible to select that default rule rather than to require active choosing. If the underlying issue is complex and unfamiliar, active choosing might be a burden rather than a benefit. But when the group is relevantly diverse, when choosing is actually preferred, and when private or public institutions cannot be trusted or lack good information about which default rule is best, active choosing has significant advantages. The question involves the costs of decisions and the costs of errors. Personalized default rules might reduce the problems associated with one-size-fits-all defaults, and thus provide most of the benefits of active choosing, at least if the relevant choice architects are informed and trustworthy. ${ }^{79}$ In many domains, personalized default rules are the wave of the future; we should expect to see a significant increase in personalization as greater information becomes available about the informed choices of diverse people.

\footnotetext{
${ }^{77}$ See Gopi Shah Goda \& Coleen Flaherty Manchester, Incorporating Employee Heterogeneity into Default Rules for Retirement Plan Selection (Nat'l Bureau of Econ. Research, Working Paper No. 16099, 2010), available at http://www.nber.org/papers/w16099.

${ }^{78}$ For a valuable discussion, see Steffan Altmann et al., Incentives and Information As Driving Forces of Default Effects (April 4, 2012) (unpublished manuscript), available at http://www.ewissl.pitt.edu/econ/files/seminars/120404_sem924_Steffen\%20Altman.pdf.

${ }^{79}$ Note that they may be trustworthy because of market incentives (in the case of private institutions) or democratic checks (in the case of public institutions). Recall, however, that active choosing has the advantage of increasing learning.
} 